\title{
Effect of rolling deformation and solution treatment on microstructure and mechanical properties of a cast duplex stainless steel
}

\author{
S K GHOSH*, D MAHATA, R ROYCHAUDHURI and R MONDAL \\ Department of Metallurgy and Materials Engineering, Bengal Engineering and Science University, Shibpur, \\ Howrah 711 103, India
}

MS received 28 June 2011; revised 21 October 2011

\begin{abstract}
The present study deals with the effect of rolling deformation and solution treatment on the microstructure and mechanical properties of a cast duplex stainless steel. Cast steel reveals acicular/Widmanstätten morphology as well as island of austenite within the $\delta$-ferrite matrix. Hot rolled samples exhibit the presence of lower volume percent of elongated band of $\delta$-ferrite $(\sim 40 \%)$ and austenite phase which convert into finer and fragmented microstructural constituents after $\mathbf{3 0 \%}$ cold deformation. By the solution treatment, the elongated and broken crystalline grains recrystallize which leads to the formation of finer grains $(<\mathbf{1 0} \mu \mathrm{m})$ of austenite. X-ray diffraction analysis has corroborated well with the above-mentioned microstructural investigation. Enhancement in hardness, yield strength and tensile strength values as well as drop in percent elongation with cold deformation increases its suitability for use in thinner sections. $30 \%$ cold rolled and solution treated sample reveals attractive combination of strength and ductility (25.22 GPa\%). The examination of fracture surface also substantiates the tensile results. The sub-surface micrographs provide the potential sites for initiation of microvoids.
\end{abstract}

Keywords. Duplex stainless steel; hot rolling; cold deformation; microstructure; tensile properties.

\section{Introduction}

Duplex stainless steels are two-phase (ferrite/austenite) alloys which combine the properties of austenitic and ferritic stainless steels. Duplex stainless steel possesses good strength, high toughness, formability, anticorrosion, biocompatibility and weldability. This grade of steel has found extensive application in heat exchangers, water heaters, pressure vessels, storage tanks, rotors, impellers and shafts, digesters and other equipment in pulp and paper production, cargo tanks in chemical tankers, desalination plants, waste gas purifiers and sea water systems (Gunn 1997; Park and Lee 2001; Cabrera et al 2003).

As received duplex stainless steel exhibits high yield strength (450-500 MPa) and high ultimate tensile strength (600-700 MPa) with excellent total elongation (20-25\%). It is known that cold rolling is a technique, applied industrially to increase the strength (Somani et al 2009). The increase in tensile strength of duplex steels is often utilized in cold worked products (Charles 1991). It has been reported that the duplex stainless steels inherently have very good chloride stress corrosion cracking resistance which is marginally affected by cold working (IMOA 1999). Thus, the approach enhances the versatility and usefulness of the steel for structural and safety applications by the way of improvement of strength with tolerable sacrifice in ductility. This combination of such properties ensures duplex steels to be used in thinner sections which result in considerable sav-

\footnotetext{
*Author for correspondence (skghosh@metal.becs.ac.in)
}

ings in weight and capital investment. In view of the above, the present study is primarily based on cold deformation of duplex stainless steels and opens the window for improving its mechanical properties through solution treatment of the cold deformed steels.

\section{Experimental}

The cast duplex stainless steel (DSS) has been considered for the present study. Result of the spectroscopic analysis conducted by using an Optical Emission Spectrometer (ARL 4460) are shown in table 1 . The steel was obtained in cast form with $\sim 30 \times 30 \mathrm{~mm}$ square cross-section and $100 \mathrm{~mm}$ in length. Then the sample was cut into four equal sizes each having $15 \times 15 \mathrm{~mm}$ square cross-section. Subsequently, all four samples were homogenized at $1100^{\circ} \mathrm{C}$ for $30 \mathrm{~min}$ to dissolve carbide and various alloying elements and were hot rolled down to a thickness of about $6 \mathrm{~mm}$ plate with a finish rolling temperature of about $800^{\circ} \mathrm{C}$. Two hot rolled and air cooled samples were cold rolled $(30 \%)$ down to a thickness of about $4 \mathrm{~mm}$. One hot and one cold rolled sample were solution heat-treated at $1020^{\circ} \mathrm{C}$ for $30 \mathrm{~min}$ to dissolve any intermetallic precipitation followed by water quenching. It needs to be mentioned that the full solution annealing treatment followed by rapid quenching is necessary to restore the mechanical properties and corrosion resistance. A flowchart of material processing has been demonstrated in figure 1. It is noteworthy, that there is no satisfactory temperature below the selected solution annealing temperature at which stress 
Table 1. Chemical composition of investigated stainless steel (wt\%).

\begin{tabular}{|c|c|c|c|c|c|c|c|c|c|}
\hline $\mathrm{C}$ & $\mathrm{Si}$ & $\mathrm{Mn}$ & $\mathrm{Ni}$ & $\mathrm{Cr}$ & Mo & $\mathrm{N}$ & $S$ & $\mathrm{P}$ & $\mathrm{Fe}$ \\
\hline 0.027 & 0.68 & 0.76 & $5 \cdot 85$ & 21.95 & $3 \cdot 05$ & $0 \cdot 16$ & 0.007 & 0.021 & Bal. \\
\hline
\end{tabular}

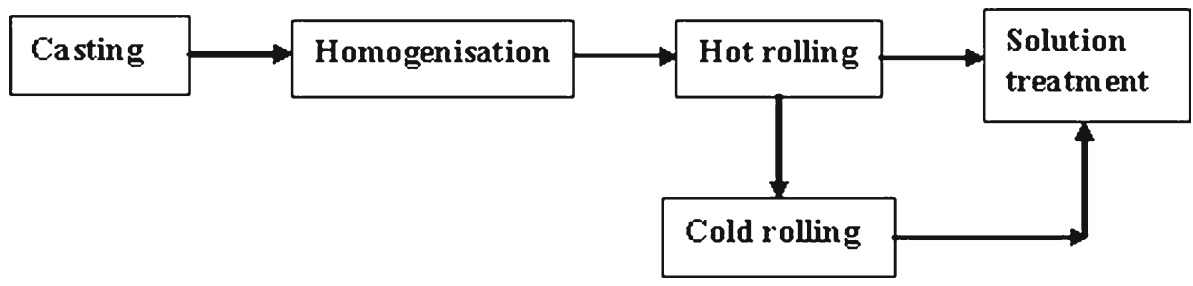

Figure 1. Flowchart of material processing.

relief can be employed without the danger of formation of intermetallic phases (IMOA 1999).

Samples prepared by following standard metallographic technique were etched using aqua regia solution $(75 \% \mathrm{HCl}$ and $25 \% \mathrm{HNO}_{3}$ mixture). Properly etched samples were examined at appropriate magnifications using optical microscope (Zeiss, Axiovert 40 Mat) and scanning electron microscope (SEM) (JEOL, JSM-5510) operated at 15 to $20 \mathrm{kV}$.

The Ferrite Meter (MF 300F+, Diverse, UK) was used for quantitative measurement of the ferrite content according to the magnetic induction method (Neumaier 1990). It has a probe that is sensitive to ferrite content in a $10 \mathrm{~mm}^{2}$ area to a depth of $\sim 1 \mathrm{~mm}$. The instrument is calibrated using the secondary world standards approved by The Welding Institute. A magnetic field is induced from a rare earth magnet into the sample via a complex magnetic path. The magnetic field strength is measured and this value is then used to compute the ferrite content. One particular advantage of the magnetic induction method for ascertaining the ferrite content is that a sigma phase, i.e. a $\mathrm{Fe}-\mathrm{Cr}$ deposit, which may have formed due to excessive ferrite contents coupled with unfavourable cool down conditions, is recognized correctly as a non-ferritic structural constituent. In a metallographic section, on the other hand, it is not easily possible to distinguish a sigma phase from a ferritic structure, which may lead to an erroneous evaluation of the ferrite content.

Small rectangular specimen $\left(20 \times 15 \times 2 \mathrm{~mm}^{3}\right)$ was mechanically polished followed by chemical polishing, using a mixture of hydrochloric acid, nitric acid and distilled water in 1:1:1 proportion, to remove the residual stress present in the surface. The X-ray diffraction study of the samples was conducted by using a Philips Diffractometer (PW 1710) with Co $\mathrm{K}_{\alpha}$ radiation with $40 \mathrm{kV}$ operating voltage, $30 \mathrm{~mA}$ current and $0.005^{\circ} 2 \theta \mathrm{s}^{-1}$ scan rate.

A Brinell-cum-Vickers hardness tester (Model: BV-250 (SPL)) was used to measure the Vickers hardness values under $30 \mathrm{~kg}$ load of the experimental steel samples. At least six indentations were taken on each sample and the average hardness value was calculated. Room temperature tensile test was carried out using a computer controlled Instron-4204 testing machine with a crosshead velocity of $0.5 \mathrm{~mm} / \mathrm{min}$. The test specimen was prepared as per ASTM Standard (ASTM: Vol. 03.01, E8M-96). The $0 \cdot 2 \%$ offset yield strength (YS), ultimate tensile strength (UTS) and percent uniform (\%UEL) and total elongation (\%TEL) were determined from the machine output. The tensile fracture surfaces as well as sub-surfaces close to the fracture surfaces were also studied under SEM.

\section{Results and discussion}

\subsection{Evolution of microstructure}

Figure 2 shows cast structure of duplex stainless steel which reveals acicular/Widmanstätten morphology as well as island of austenite $(\gamma)$ within $\delta$-ferrite matrix $(60.78 \pm 1.53 \%)$. During solidification, duplex stainless steel first solidifies as $\delta$-ferrite followed by austenite formation at the ferrite grain boundaries during continuous cooling.

Figures 3(a) and (b) show SEM and optical micrograph, respectively of the hot rolled steel followed by air cooling. Both micrographs essentially reveal austenite and ferrite $(39.11 \pm 1.33 \%)$ grains which are elongated along the rolling direction. It is known that the nucleation of secondary austenite $\left(\gamma^{\prime}\right)$ phase occurs through the $\delta \rightarrow \gamma^{\prime}$ transformation (Martins and Casteletti 2005). It can be conjectured that the reduction of ferrite content in the present hot rolled steel is attributed to the formation of $\gamma^{\prime}$ inside the $\delta$-ferrite grain. Such type of formation of secondary $\gamma^{\prime}$ phase inside the $\delta$ ferrite grain was elegantly demonstrated in the microstructure of cast 2205 DSS after hot deformation at $950{ }^{\circ} \mathrm{C}$ (Fan et al 2009). Identification of ferrite and austenite were made using Beraha's tint reagent (Van der Voort 1984) which was considered as an effective method for stainless steel where $\delta$-ferrite is coloured and austenite remains unaffected in the optical micrograph (figure 2(b)).

Figure 4(a) is SEM micrograph of the hot rolled steel which was solution treated at $1020^{\circ} \mathrm{C}$ for $30 \mathrm{~min}$ followed by water quenching. As a consequence of solution treatment, the elongated ferrite and austenite hot rolled laths were predominantly transformed into almost equiaxed morphology. 


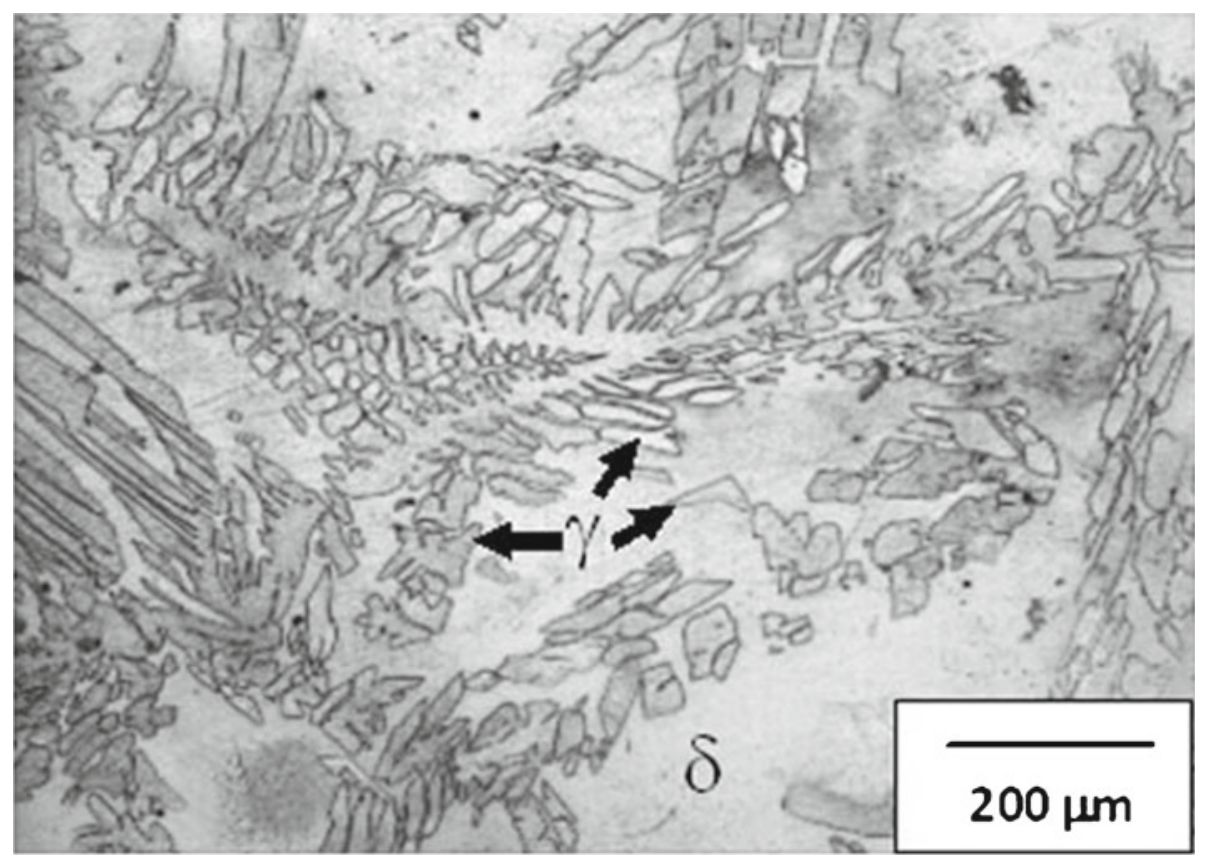

Figure 2. Optical micrograph of cast duplex stainless steel sample.
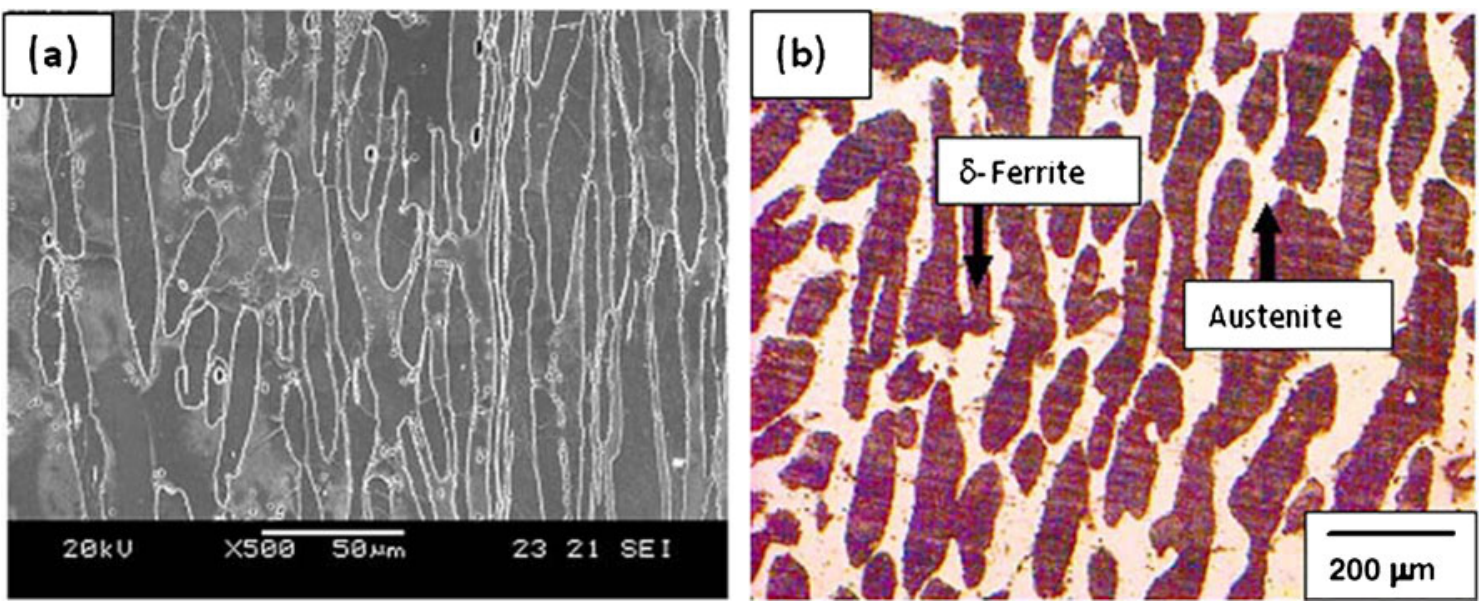

Figure 3. (a) SEM micrograph of hot rolled sample and (b) optical micrograph of same sample showing selective colour etching by Beraha's reagent $\left(15 \mathrm{~mL} \mathrm{HCl}, 85 \mathrm{~mL}\right.$ water and $\left.1 \mathrm{~g} \mathrm{~K}_{2} \mathrm{~S}_{2} \mathrm{O}_{5}\right)$.

It is noteworthy that the $\delta$-ferrite has higher stacking fault energy than that of austenite and dynamic recovery takes place in $\delta$-ferrite more easily (McQueen and Bourell 1986). The austenite undergoes limited dynamic recovery and more prone to dynamic recrystallization when the dislocation density reaches a critical value. The transformation of band-form of austenite to globular form is attributed to the static recrystallization of austenite during solution treatment. The volume percent of ferrite is marginally higher i.e. $42.02 \pm 1.32 \%$, as compared to hot rolled sample and is in agreement with the results in other duplex stainless steels reported earlier (Nilsson 1992; Lai et al 1995). This trend is in good agreement with the ternary $\mathrm{Fe}-\mathrm{Cr}-\mathrm{Ni}$ constitution diagram at $70 \% \mathrm{Fe}$ (Gunn 1997).
Figure 4(b) is SEM micrograph of the hot rolled steel followed by $30 \%$ cold deformation. Austenite and ferrite grains were elongated along with rolling direction and at the same time became fragmented. The volume percent of the ferrite phases is higher i.e. $51.41 \pm 2.23 \%$. It needs to be mentioned that all magnetic components are documented in the Ferrite Meter, i.e. in addition to ferritic components, transformation of austenite into martensite during cold deformation should also be considered. It may be mentioned that cold rolling imparts enough work into the steel to get it to change the arrangement of the atoms to get ferromagnetic properties. Some of the things that could affect this include composition - higher chromium, or molybdenum contents, or lower nickel contents. Hence cold working is supposed to increase 

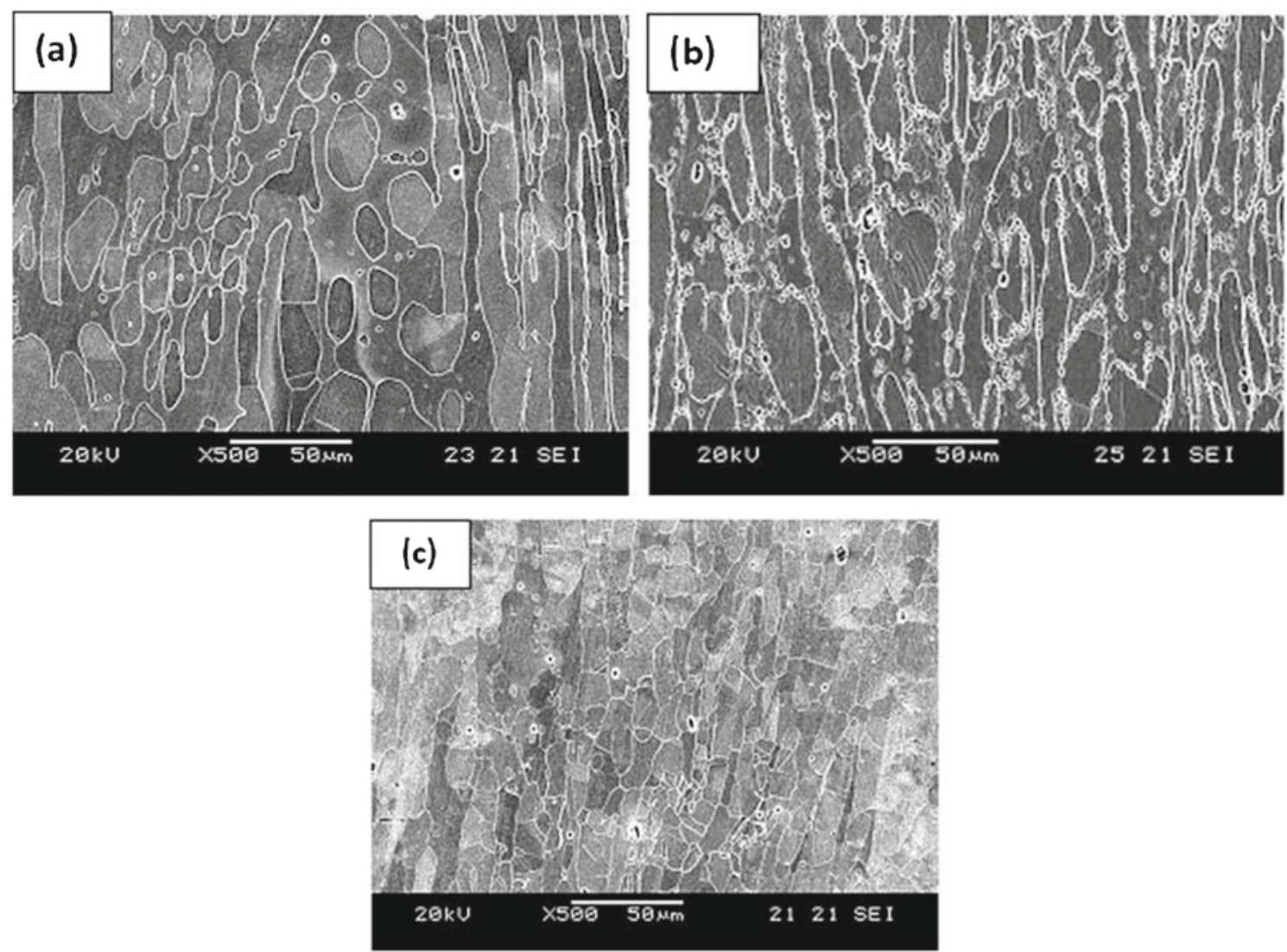

Figure 4. SEM micrographs of (a) hot rolled and solution treated $\left(1020^{\circ} \mathrm{C}, 30 \mathrm{~min}\right)$ sample, $(\mathbf{b})$ cold rolled $(30 \%)$ sample and (c) cold rolled (30\%) and solution treated sample.

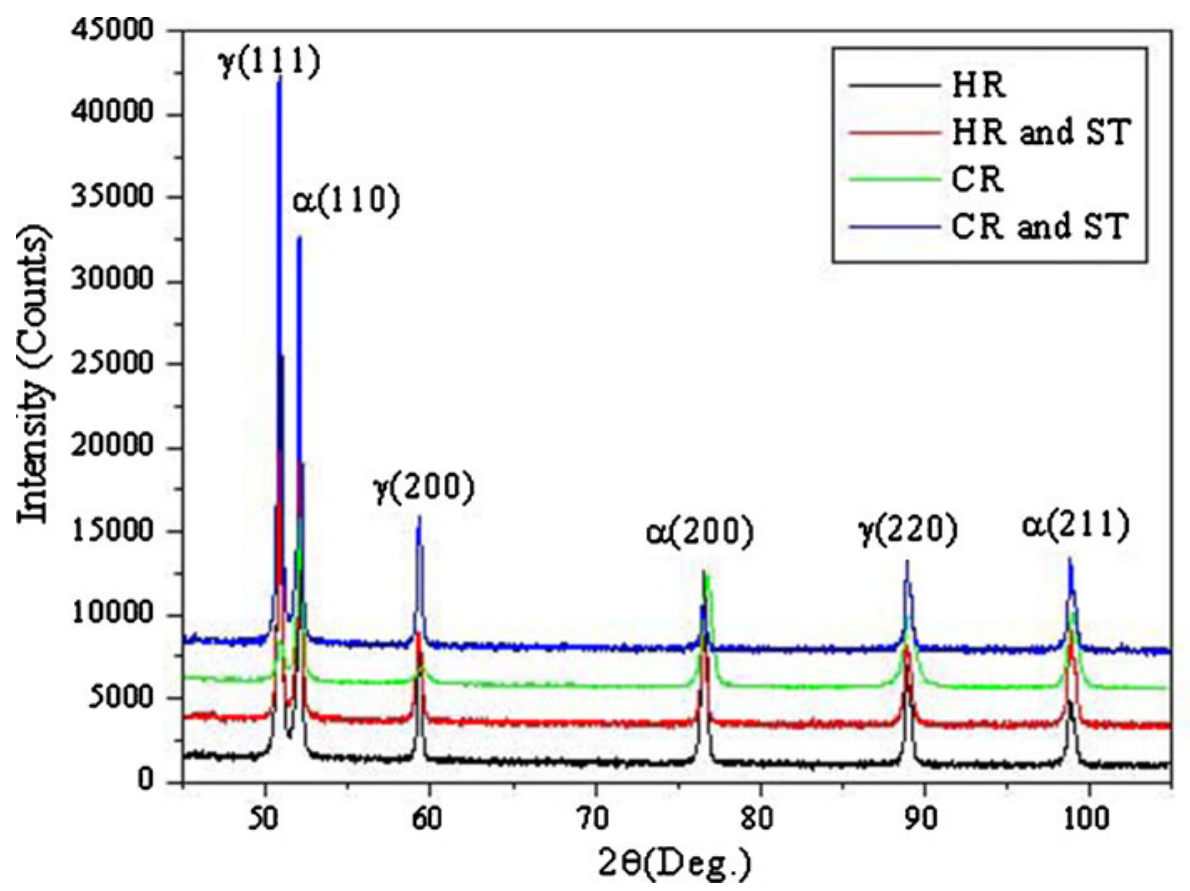

Figure 5. X-ray diffraction profiles of hot rolled (HR), 30\% cold rolled (CR), hot rolled and cold rolled samples subjected to solution treatment (ST) at $1020^{\circ} \mathrm{C}$ for 30 min duration. 


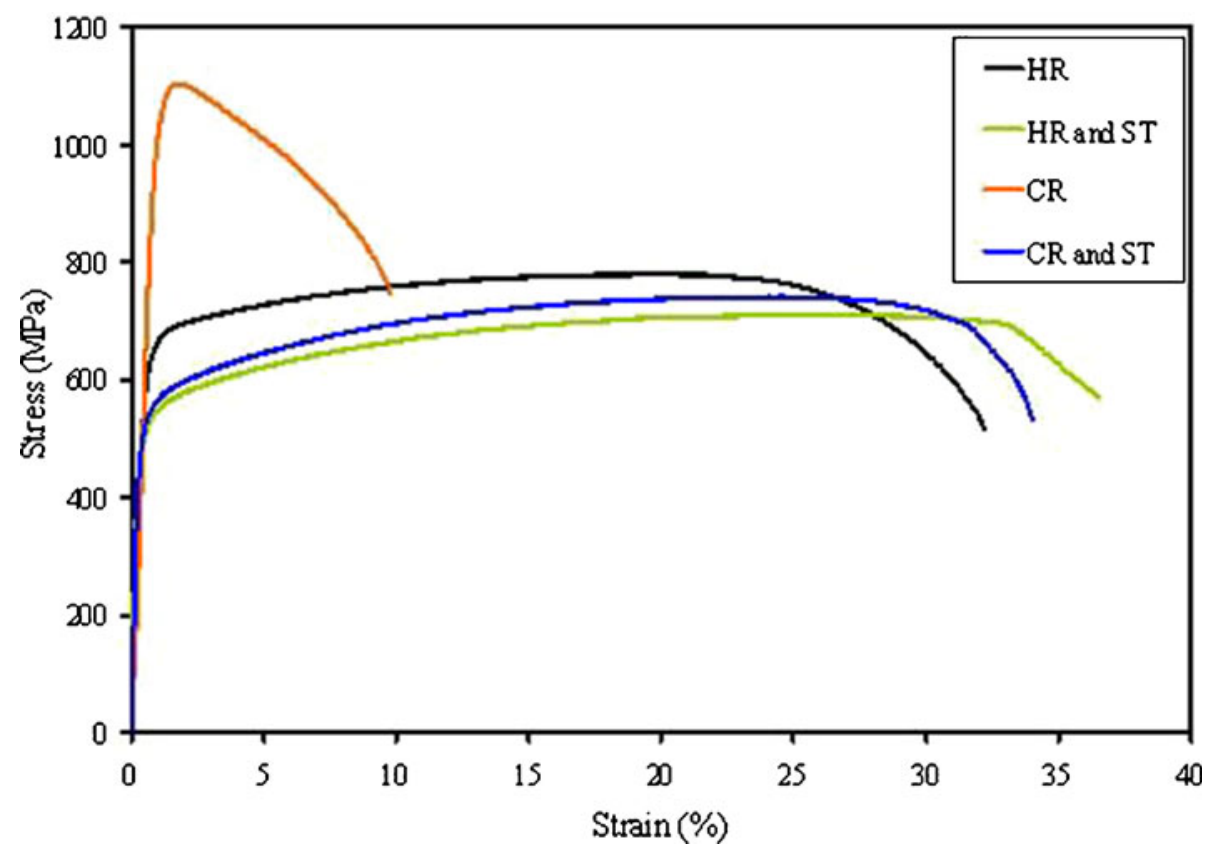

Figure 6. Engineering stress-strain curve of DSS samples after various treatments.

Table 2. Hardness and tensile test results of DSS samples after various treatments.

\begin{tabular}{|c|c|c|c|c|c|c|c|}
\hline Sl. No. & Treatments & $\begin{array}{l}\text { Bulk hardness } \\
\text { (VHN) }\end{array}$ & $\begin{array}{c}0.2 \% \text { offset YS } \\
(\mathrm{MPa})\end{array}$ & UTS (MPa) & $\operatorname{UEL}(\%)$ & TEL $(\%)$ & $\begin{array}{c}\text { UTS } \times \text { TEL } \\
(\mathrm{GPa} \%)\end{array}$ \\
\hline 1. & As cast & 220 & 450 & 620 & $14 \cdot 62$ & $25 \cdot 12$ & $15 \cdot 57$ \\
\hline 2. & Hot rolled and air cooled & 242 & 523 & 779 & $19 \cdot 72$ & $32 \cdot 19$ & $25 \cdot 08$ \\
\hline 3. & Hot rolled and solution treated & 215 & 473 & 710 & $26 \cdot 13$ & $36 \cdot 52$ & $25 \cdot 93$ \\
\hline 4. & Cold rolled $(30 \%)$ & 322 & 1017 & 1104 & $01 \cdot 84$ & $09 \cdot 76$ & $10 \cdot 77$ \\
\hline 5. & Cold rolled and solution treated & 225 & 499 & 741 & $24 \cdot 05$ & $34 \cdot 04$ & $25 \cdot 22$ \\
\hline
\end{tabular}

the ferrite content in the magnetic test. Figure 4(b) further reveals that the preferential etching attacks at the interface which is attributed to the accommodation of grain boundary strain after cold deformation. Figure 4(c) is SEM micrograph of $30 \%$ cold deformed sample which was subjected to solution treatment at $1020^{\circ} \mathrm{C}$ for $30 \mathrm{~min}$. The volume percent of the ferrite phase is drastically reduced to $37.18 \pm 1.45 \%$ after solution treatment which is an indication of transformation of ferrite into austenite (i.e. $\delta \rightarrow \gamma$ ) during solution treatment. Figure 4(c) further reveals that the preferential etching attack at the interface after cold deformation (figure 4(b)) is absent here probably due to the release of internal stress after solution treatment. By solution treatment, the cold worked lattice recovers and elongated and broken crystalline grains recrystallize which leads to the formation of finer grains $(<10 \mu \mathrm{m})$ of austenite.

\section{$3.2 X$-ray diffraction}

Figure 5 presents the X-ray diffraction profiles of the hot rolled and cold rolled and samples subjected to solution treatment (ST) at $1020^{\circ} \mathrm{C}$ for 30 min duration. In the case of the hot rolled sample, the (110), (200) and (211) peaks of the bcc ferrite $(\alpha)$ phase are clearly revealed along with the (111), (200), (220) peaks characterizing the $f c c$ austenite $(\gamma)$ phase. XRD patterns of cold rolled or solution treated samples do not reveal any additional peak related to other phases. It may be mentioned that residual stresses present in the deformed sheet specimen could be relieved after solution treatment at $1020^{\circ} \mathrm{C}$ as well as no other phases were introduced after solution treatment. In the present study, the existence of any precipitation of intermetallic phases could not be identified in X-ray diffraction result. It implies that the volume percent of those embrittling phases (if any) was inadequate for estimation by X-ray diffraction. Thus, the X-ray diffraction result has consequently corroborated the microstructural evolution.

\subsection{Mechanical properties}

Figure 6 and table 2 present mechanical properties of duplex stainless steel samples obtained after various treatments. Cast sample records the lowest yield strength (450 MPa) 
and tensile strength (620 MPa) and lesser elongation (25\%) because of the chemical segregation and presence of acicular/Widmanstätten type dispersed austenite phase in $\delta$-ferrite matrix (figure 2). The improved hardness ( $242 \mathrm{VHN}$ ) and tensile properties of the hot rolled sample are outcome of the higher austenite/ferrite ratio (1.56) and elongated phase constituents (figure 3(a)). High hardness (322 VHN) and extremely high yield strength (1017 MPa) at room temperature, more than twice that of cast sample as well as highest ultimate tensile strength (1104 MPa) and lowest elongation $(\sim 10 \%)$ are obtained after $30 \%$ cold rolling due to the work hardening behaviour of the constituent phases. $30 \%$ cold rolled and solution treated sample exhibits attractive combination of strength and ductility ((UTS $\times$ TEL) (Sugimoto et al 2000) $=25 \cdot 22 \mathrm{GPa} \%$ ). Generally solution treated samples have exhibited drop of hardness value, continuous yielding behaviour and higher uniform elongation (24$26 \%$ ) which are desirable for formability. This behaviour is attributed to the higher range of austenite to ferrite ratio $(1.38-1.68)$ as well as transformation from acicular to globular austenite phase obtained after solution treatment (figures 4(a) and (c)). After solution treatment the ferrite content of the cold rolled sample reduces but at the same time austenite grain size reduces (figure 4(c)) which basically increases the strength (table 2). This is attributed to the fact that the austenite is significantly stronger than the ferrite. The presence of residual stress in case of cold rolled sample after solution treatment is expected to sustain marginally higher yield strength (499 MPa).

Strain is mostly accommodated by the $\delta$-ferrite phase at the early stage of tensile deformation (Balacin et al 2000). At higher strain, load is transferred from $\delta$-ferrite to austenite leading to increment of dislocation density in the latter. The yield strength is governed by ferrite and austenite primarily controls the tensile strength of steel. The total elongation imposed on DSS is the elongation accommodated by $\delta$-ferrite and austenite phase. It may be mentioned that the tensile properties of the composite material like present experimental steels are controlled by the $\delta$-ferrite and by the amount, shape and distribution of the austenite.
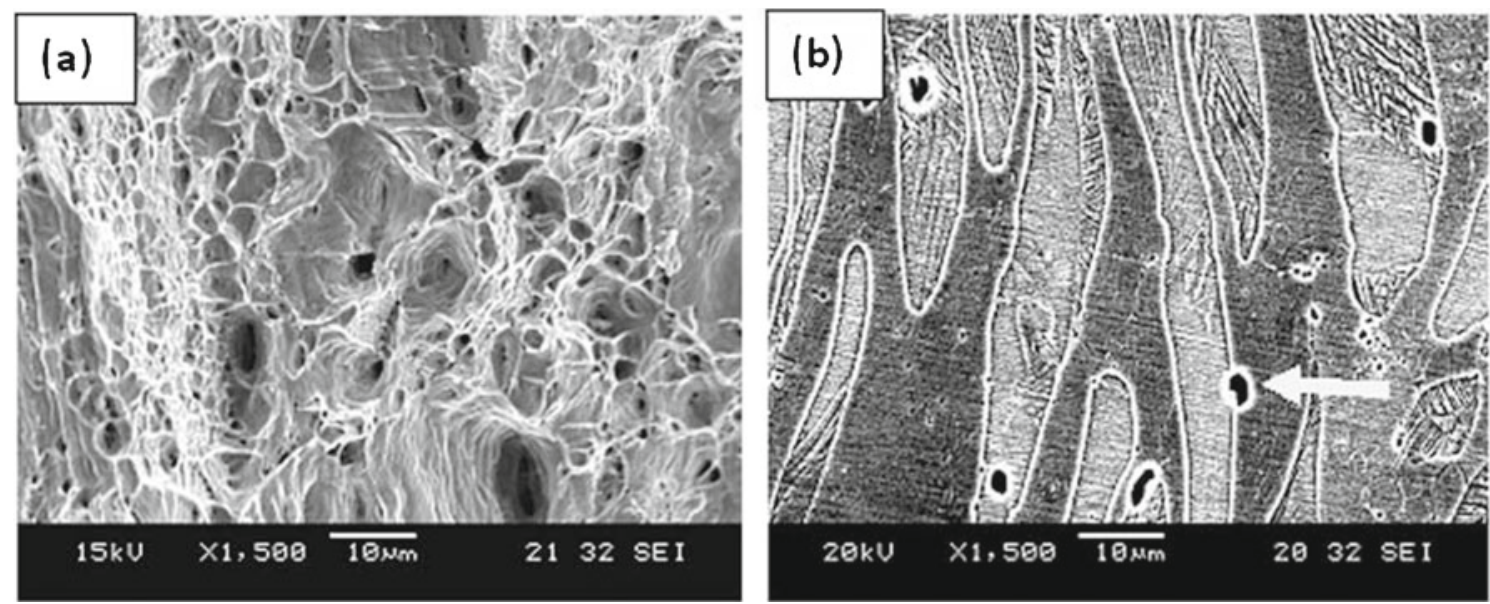

Figure 7. SEM micrographs of (a) fracture surface and (b) sub-surface of hot rolled sample.
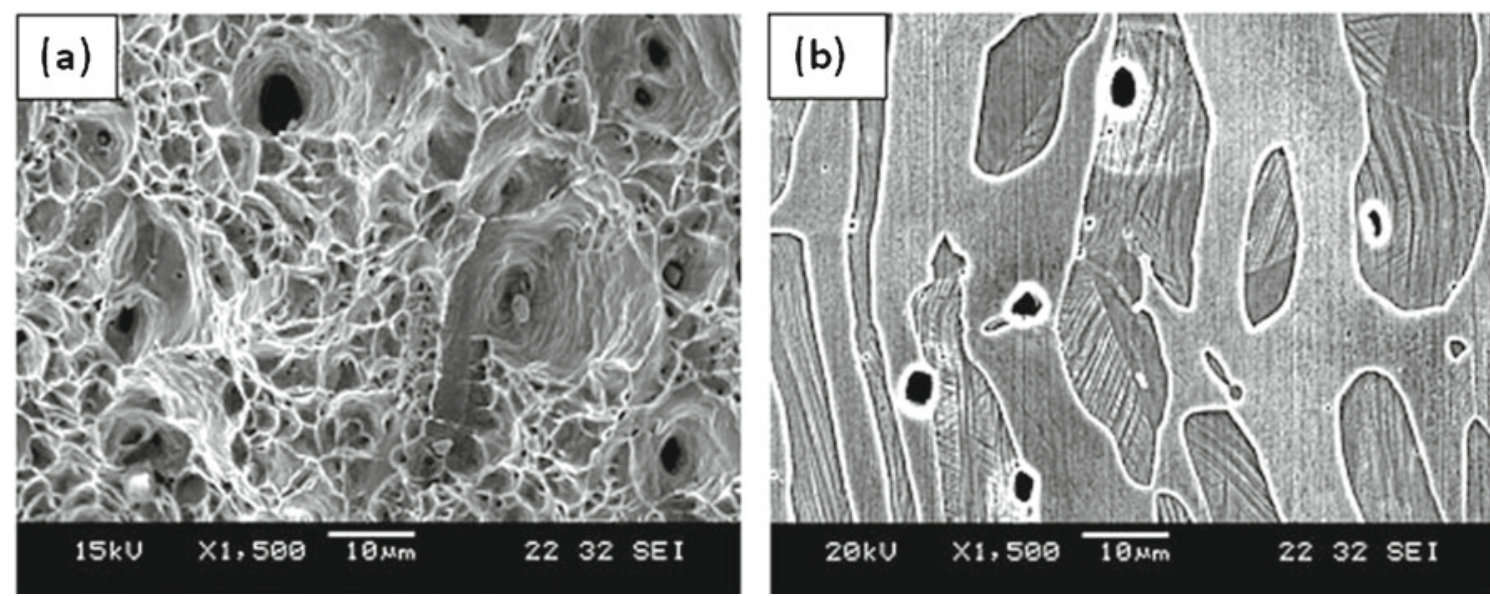

Figure 8. SEM micrographs of (a) fracture surface and (b) sub-surface of hot rolled and solution treated sample. 


\subsection{Fracture surface and sub-surface}

To understand the micro-mechanism of fracture, tensile fracture surfaces and sub-surfaces just underneath the fracture surfaces have been studied using SEM. The tensile fracture surface of hot rolled specimen (figure 7(a)) reveals predominantly ductile fracture with varying dimple size and depths. The size of the dimple is extremely fine which indicates higher ductility (32\%). Sub-surface micrograph (figure 7(b)) reveals the frequent nucleation of micro-voids at the austenite/ferrite interface (denoted by white arrow). The microvoids are elongated toward the tensile loading direction indicating higher ductility.

The fractograph of hot rolled and solution treated $\left(1020^{\circ} \mathrm{C}, 30 \mathrm{~min}\right)$ specimen as shown in figure 8 (a) shows the typical ductile nature. The fractographic features of the sample are in conformity with the corresponding percent elongation values $(36 \%)$. The sub-surface micrograph (figure 8(b)) clearly indicates that the microvoids are essentially nucleated along the austenite/ferrite which results in slow void coalescence; thereby tensile fracture becomes predominantly ductile in nature.

The fractograph of cold deformed (30\%) specimen as shown in figure 9(a) shows the quasi-brittle nature. The subsurface micrograph (figure 9(b)) demonstrates that the voids are nucleated from the austenite/ferrite interface. The quasi brittle fracture may be attributed to the presence of arrested stress after cold deformation which accelerates the motion of advancing crack.

The tensile fracture surface of cold rolled and solution treated specimen (figure 10(a)) reveals predominantly ductile fracture with varying dimple size and depths which indicates good ductility (34\%). Sub-surface micrograph (figure 10(b)) reveals that the microvoids appear to be nearly spherical. The microvoids are nucleated within the grains of $\delta$-ferrite as well as in the ferrite/austenite interface. Due to the high surface free energy of dislocation cell walls formed within $\delta$-ferrite during solution treatment, the initiation of micro-cracks at these interfaces can be considered as a rational outcome. The release of internal stress
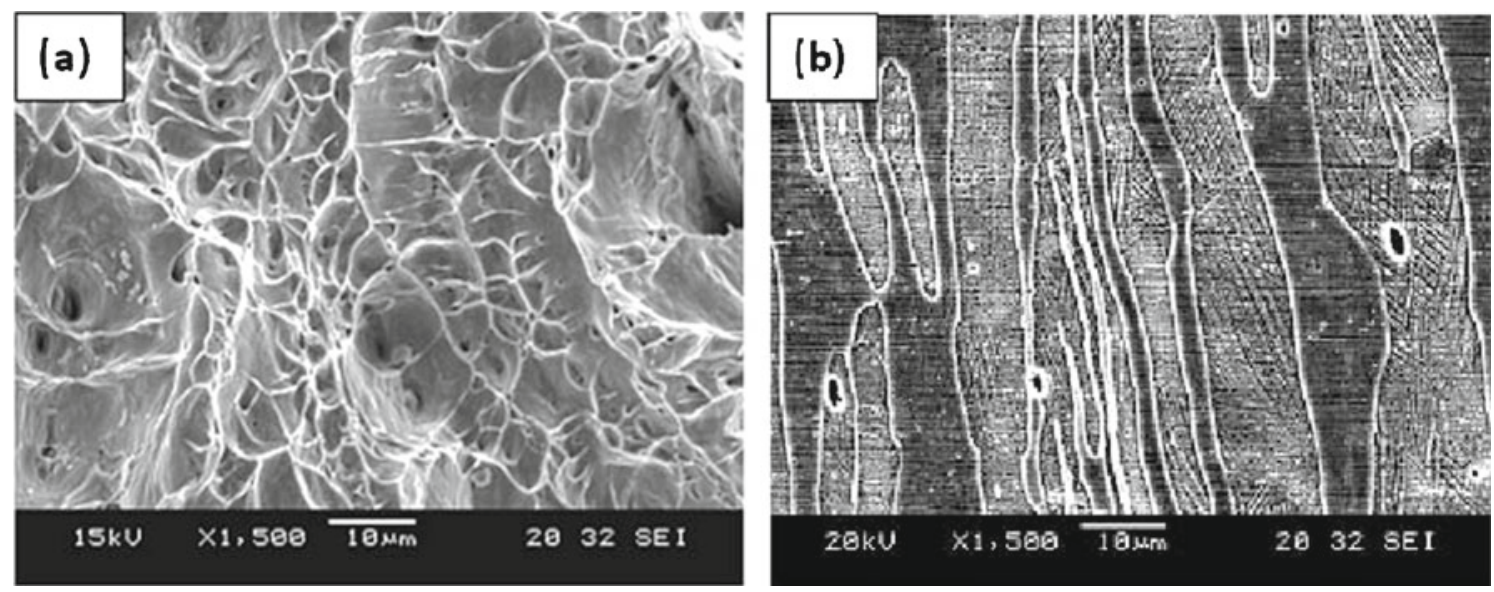

Figure 9. SEM micrographs of (a) fracture surface and (b) sub-surface of cold rolled (30\%) sample.
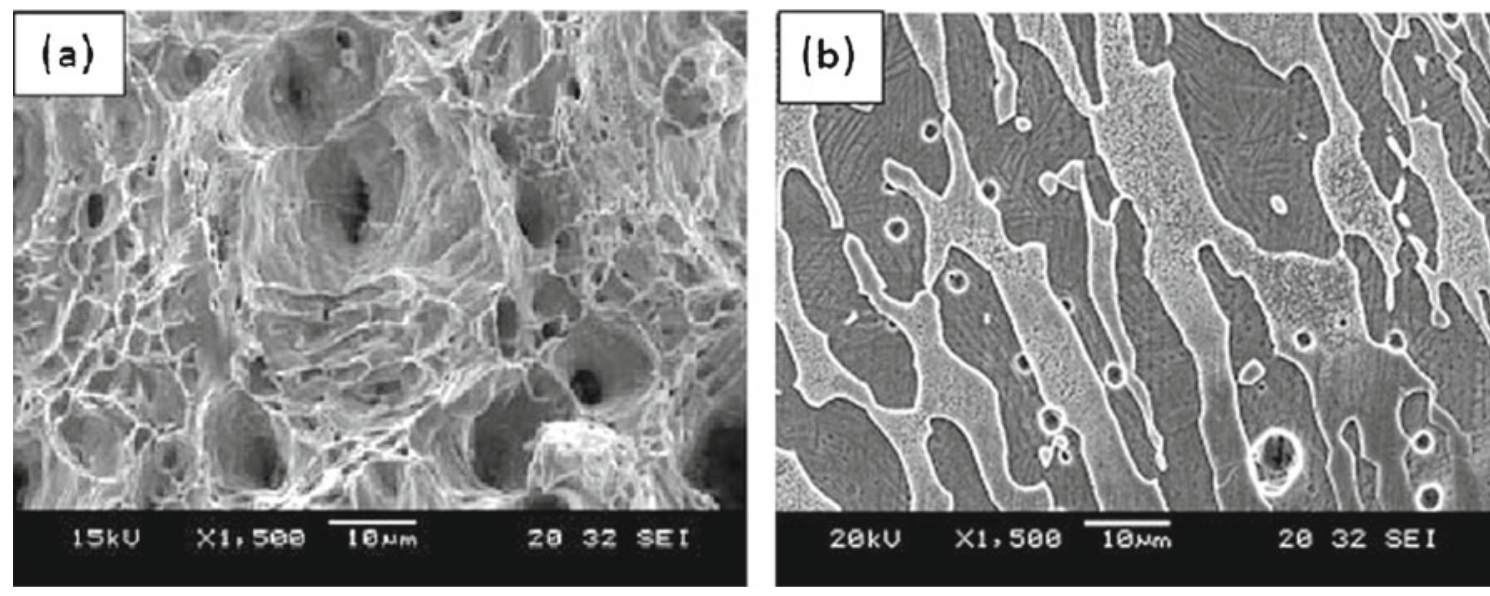

Figure 10. SEM micrographs of (a) fracture surface and (b) sub-surface of cold rolled and solution treated sample. 
and finer recrystallized grains of solution treated samples are favourable for increased plasticity. As a consequence, the sample reveals higher percent elongation and fracture surfaces are essentially ductile in nature.

\section{Conclusions}

(I) Microstructural examination has demonstrated the presence of ferrite and austenite phase in dissimilar volume fraction in all experimental steel samples. No precipitation or intermetallic phases appear on the micrograph. $30 \%$ cold deformation leads to the fragmentation of the constituent phases. Solution treatment at $1020^{\circ} \mathrm{C}$ for $30 \mathrm{~min}$ leads to the formation of almost equiaxed grains of austenite. No grain growth is observed up to $1020^{\circ} \mathrm{C}$.

(II) $\mathrm{X}$-ray diffraction analysis has corroborated well with the microstructural examination.

(III) Enhancement in hardness, yield strength and tensile strength values as well as drop in percent elongation with cold deformation increases its suitability for use in thinner sections. $30 \%$ cold rolled and solution treated sample reveals attractive combination of strength and ductility (25.22 GPa\%).

(IV) The fractographic observation substantiates the results obtained from tensile testing. The sub-surface micrographs provide potential sites for the initiation of microvoids.

\section{References}

Balacin O, Hoffmann W A M and Jonas J J 2000 Metall. Mater. Trans. A31 1353

Cabrera J M, Mateo A, Lianes L, Prado J M and Anglada M 2003 J. Mater. Process. Technol. 143-144 321

Charles J 1991 Proc. conf. duplex stainless steels'91 (Paris: Beaune, Les Editions de Physique) 1151

Fan G W, Liu J, Han P D and Qiao G J 2009 Mater. Sci. Eng. A515 108

Gunn R N 1997 Duplex stainless steels-microstructure, properties and applications (Cambridge, England: Abington Publishing)

International Molybdenum Association 1999 Practical guidelines for the fabrication of duplex stainless steels, Shop Sheet 101, London

Lai J K L, Wong K W and Li D J 1995 Mater. Sci. Eng. A203 356

Martins M and Casteletti L C 2005 Mater. Charact. 55225

McQueen H J and Bourell D L 1986 Formability and metallurgical structure, in Proc. symposium (eds) A K Sachdev and J D Embury (Warrendale: TMS) p. 341

Neumaier P 1990 Mater. Eval. 481065

Nilsson J O 1992 Mater. Sci. Technol. 8685

Park Y H and Lee Z H 2001 Mater. Sci. Eng. A297 78

Somani M C, Juntunen P, Karjalainen L P, Misra R D K and Kyröläinen A 2009 Metall. Mater. Trans. A40 729

Sugimoto K, Sakaguchi J, Iida T and Kashima T 2000 ISIJ Int. 40 920

Van der Voort G F 1984 Metallography: Principles and practice (New York: McGraw-Hill Book Company) 